\title{
Avocadoes and Chinese Cuisine
}

Ms. Edith Gomez

Trade and Investment Queensland

Brisbane

Australia

Dr Robin E Roberts

Griffith Asia Institute, Griffith University

Australia

Keywords: Consumer behaviour, marketing, qualitative, consumption, pos material.

\section{Abstract}

This paper presents the results of qualitative research undertaken in Singapore with consumers from various Asian ethnic backgrounds, with emphasis on Chinese-ethnic consumers. The study provides an understanding of consumers' attitudes, behaviours and beliefs towards avocadoes Persea Americana). It also presents the results of unstructured interviews conducted with representatives of the food service industry in Singapore. The study found that although avocados are gaining popularity in Asian markets consumption is still relatively low, with only a small portion of consumers purchasing them regularly. Avocados are not popular with Chinese consumers, as most find it hard to integrate the fruit in Chinese cooking. Avocados are not commonly used in Asian cuisine and are only used for entertaining guests during gatherings. Furthermore, as avocados are known as 'butter fruit' in Chinese, there are misconceptions as to the negative health aspects of the fruit. The Australian avocado industry is taking active steps to gain market access to the expanding Asian consumer market. As the phytosanitary protocol development process is time consuming, costly and resource intensive, the industry needs to ensure that such investment translates into trade success. Understanding consumer's attitudes and interaction with avocados in the first step to plan market development activities and ensure export success. This study concludes that to increase avocado consumption with consumers from Chinese background, greater awareness of the different uses of avocados is needed and more consumer information is required to dispel any confusion about the health attributes of the fruit. 


\section{INTRODUCTION}

The general consensus has been that Asians from a Chinese-ethnic background would not find avocados (Persea Americana) appealing (Brescia 2012). Furthermore, as avocados are known as 'butter fruit' in Chinese, there was the belief the Chinese associated avocados with the negative health attributes of the fruit. However over the last decade, the market for fresh avocadoes has slowly gained momentum, particularly in Japan, Singapore, Hong Kong and, just recently, in China. In 2005, Asia imported just $\$ 69$ million, but by 2013 imports were valued at over \$213 million (TradeMap 2015). Japan is by far the largest importer with over $75 \%$ of all Asian imports in 2013. Although avocadoes have not been part of the traditional Chinese diet, avocado imports to mainland China have experienced exponential growth in recent years, with direct imports going from almost non-existent before 2010 to $\$ 11.2$ million in 2014 (TradeMap 2015). Higher disposable income and a greater demand for imported food could explain the rapid rise of avocado imports. Studies of food demand in China have shown that changing consumer patterns as a result of increases in income have resulted in higher demand for quality food, including fresh fruits (Gale and Huang 2007, Yu and Abler 2009). Furthermore, positive attitudes towards imported fruit (Sun and Collins 2002) and publicity about food poisoning incidents and high chemical residues (Marks and Bean 2005) have contributed to the growth in imported foods.

With most Chinese having had no much exposure to avocados, consumer demand in China is still very low. Currently, avocados have not been sold in the local supermarkets, and even foreign-owned retailers rarely stock the fruit. Avocado was a recent introduction to China, with the first trial plantings occurring in Guangdong in 1925 (Kangde and Jiannan 2000). Apart from some large hotels in cities in Beijing and Shanghai, very little interest was shown in the fruit, thus limiting the expansion of a local industry. Furthermore, as prior to 2010 phytosanitary protocols had not being negotiated, market access restrictions prohibited avocados from entering the country legally and being sold widely in supermarkets. Avocadoes did enter the country sporadically through informal channels. Prior to 2012 up to $93 \%$ of all avocado imports to Hong Kong were re-exported to China (TradeMap 2015). Avocado producing countries saw this emerging demand and begun taking active steps to supply directly to China. Mexico, the USA, Chile, New Zealand, Peru and Australia competed to gain direct market access. Mexico, the USA and Chile were recently granted access and are now developing aggressive strategies to secure market share and become the main supplier to the Chinese consumer market. Multinational companies such as Mission Produce have developed strategic partnership with local companies and promoting avocados in major Chinese cities (FreshPlaza 2014).

The Australian avocado industry has also been trying to secure market access to the Chinese market for a number of years. Negotiations are still taking place, but the industry has already embarked in relationship building and market research activities to prepare growers for when access is granted (Honan 2014). Currently, most of Australian's exports are going to the Asia-Pacific region. In 2013 total exports were valued at $\$ 7.13$ million, with the main markets being Singapore (\$3.4 million), Malaysia ( $\$ 1.67$ million) and Thailand (\$1.85 million) (TradeMap 2015). Due to market access restrictions, the Thai market was halted in 2014, casing overall Australia's exports to drop to $\$ 5.32$ million. With the closing down of the Thai market, there has been an added impetus for the Australian industry to gain access to the growing Chinese market. Singapore, the most important Australian market, has grown by 72\% from 2009 to 2014 (TradeMap 2015), and the Australian industry is trying to emulate the Singapore success in China. 
However, despite increasing interest in supplying avocados to Asia, particularly to China, no consumer research had been undertaken to understand the Asian avocado consumer. Furthermore, no research has been done to identify Chinese-ethnic consumers' attitudes and buying behavior towards avocadoes (Sun and Collins 2002). Literature covering avocado or even tropical fruit purchasing behavior is limited. However, as the Australia industry invest in securing market access to China and in maintaining its presence in Singapore and Malaysia, an understanding of the purchasing behavior of Chinese-ethnic consumers is critical to succeed in Asia.

The paper seeks to provide an exploratory insight of consumers' attitudes, behaviours and beliefs toward avocado in Singapore. Qualitative research was undertaken in Singapore with consumers from various ethnic backgrounds, with emphasis on consumers from a Chinese-ethnic background. Research was also undertaken with representatives of the food service industry to explore how avocados can fit into Chinese cuisine. Consumer research could not be conducted in mainland China, as Australian avocados are not allowed in China and no avocados from other countries was available at time of the research. It is presumed that some of the learning from this research can be extrapolated to consumers from a Chinese ethnic background in other regions, such as mainland China.

This paper presents the results of qualitative research undertaken in Singapore with consumers from various Asian ethnic backgrounds, with emphasis on Chinese consumers. The research objectives are to: (1) understand consumer habits and attitudes towards avocados in Singapore; (2) identify motivators and key barriers for purchasing avocados; (3) explore reactions towards Australian avocados in the Singapore market; (4) obtain feedback on promotional material and marketing messages.

\section{MATERIALS AND METHODS}

\section{Subjects}

Exploratory research in the form of focus group sessions was conducted to gather information on consumer attitudes and behaviour as regards consumption of avocadoes. This data gathering method is generally used to collect information about consumer behavior and is suitable for food consumption research (Morgan and Krueger 1993).

The focus groups were conducted in Singapore. Singapore was chosen because of its mixed ethnic composition (for example Chinese, Malay, Indian, minority ethnicities). Four focus groups sessions were conducted, each consisting of eight to ten respondents, involving a total of 38 participants. Participants were chosen according to ethnicity, incidence of avocado consumption and avocado purchasing behaviour. Additionally, indepth semi-structure interviews with importers, wholesalers and retailers of avocados were conducted in May 2012 in Singapore. The objective of the survey was to identify key challenges and opportunities for the Australian avocado industry. A semi-structured questionnaire was administered, with themes relating to logistics, post-harvest handling practices, merchandising, consumer perception and intention to grow market.

\section{Data analysis}

The responses obtained in the focus group sessions and the trade interviews were analysed using thematic analysis, which focused on examining themes within the data set presented (Daly, Kellehear et al. 1997, Attride-Stirling 2001). Thematic analysis was used because it can easily identify key sub-themes by combining and cataloguing patterns 
emerging from the focus group discussions (Leininger 1985). Transcripts and tapes were first analysed by the moderator and by the research team. The research team reviewed the transcripts, coding and identifying key concepts. Sub-themes emerged relating to the role of fruit in the Singaporean diet, attitudes towards avocados, consumption patterns, buying behavior, and others. These sub-themes provide a comprehensive view of the Singaporean avocado consumer and of the Singapore avocado market.

Furthermore, general assumptions can be made about the use of avocados in Chinese cooking in Singapore.

\section{RESULTS AND DISCUSSION}

\section{Singapore attitudes toward food}

Given the easy accessibility and variety of cuisine currently available in Singapore, eating out is the social norm. Cooking at home and using new and fresh ingredients is a limited occurrence. Local hawker food is a very popular option, given its affordability, variety and familiarity to most Singaporeans. Desserts that are visually pleasing, and sweet and rich tastes are appealing. There is an increasing tendency to demand heathier foods, with fruit salads and fruit juices becoming popular. Singaporean are seeking and learning about food and new places to eat out through the use of blogs, website, and social media. Food bloggers also provide simple recipes to those interested in trying new cooking styles and novel ingredients at home. Generally, respondents from a Malay and Indian backgrounds prefer to use more spices in their meals; Chinese prefer stir-fried and soup dishes that are not that spicy.

\section{The role of fruit in Singaporean diets}

Fruits that are healthy, convenient to use and sweet tasting are preferred. Most frequent fruits consumed tend to be temperate fruits such as pear, apple, orange, strawberry and grapes. Popular tropical fruits are mangoes, pineapple, bananas, watermelons and papaya. Avocado is a popular fruit, but consumed less frequently, in the same category as jackfruit. Chinese users in particularly stated that they preferred exotics and premium fruits, such as avocado.

Taste, convenience of use and health appear to be the main determinants of fruit consumption. Respondents cited vitamins and antioxidants benefits as well as fruits as aids to ailments such as constipation, heart problems and obesity as influencing consumption. The health benefits associated with avocado consumption appear to be important to both Chinese and mixed ethnicity users. The convenience of buying and storing fruits at home and at the workplace was also a major factor affecting purchase and consumption. In addition, cultural uses of fruit were adhered by most respondents. For example, during Chinese new year pomelo and oranges are widely consumed' for Malay weddings, grapes and peaches.

\section{Avocado key associations}

During the discussion there was low-to-medium recall for avocadoes when asked most popular fruits consumed. However, when prompted, respondents could easily recall the variety of dishes using avocadoes (for example sushi, shakes and dips) and cited the health benefits such as its high nutritional value, cholesterol-free status and skin care properties. Associations with Indonesian and Mexican cuisine were also common. Key associations related to health (good for the heart, cholesterol-free, nutritious, good for skin 
care), taste (creamy, buttery, nutty, not very sweet, no smell) and food usage (sandwiches, salads, shakes, ice-cream, sushi, dips and condiments).

Most consider avocados to be a 'unique' and 'premium' fruit characterised by its distinctive features: "I mean first time tying it out you think it's a fruit, but it is not sweet. It does not look like a typical fruit, so it is something different, not like regular fruits". Avocadoes are considered a recent occurrence in Singapore, with most introduced to the fruit by friends usually in the form of juices or milkshakes.

\section{Key attributes of avocados}

The common attributes across all groups was the perceived health properties of avocados, particularly with references to aiding in reducing cholesterol levels and lessening the risks of a heart attack: "It's a healthy fruit, low in cholesterol. It is high in good cholesterol, and lowers bad cholesterol. It has a lot of food fats in it" (Chinese user). Mixed ethnicity participants largely appreciated the vitamins, good fats and nutrients in the avocado.

Respondents acknowledged that avocadoes are high in fibre, vitamins, nutrients and anti-oxidants. Although, there was a consensus from all groups relating to the health properties of avocados, overall, Chinese consumers knowledge was well developed.

While most appreciate the health benefits of avocadoes, the taste of avocados by itself has low appeal, especially for the Chinese-ethnic consumers. Avocadoes are considered to be a taste catalyst when used as an ingredient, rather than a taste provider: "Health is the only reason why I eat it. Avocado doesn't really have a taste. So it's not tasty like oranges, there is no reason why I would eat avocado by itself (mixed ethnicity user). Versatility or ease of use was also identified as a key benefit of avocadoes as the fruit can easily be adapted to a number of savoury or sweet recipes. Due to its soft texture and subtle flavor, avocadoes can be used in a wide range of dishes from Indonesian shakes to Mexican guacamole.

\section{Avocado usage}

Avocados are consumed both at home and when eating out. The mixed ethnicity and the trade group groups were more likely to take risks with the fruit and consume avocados in a wider range of dishes from savoury to sweet dishes. Chinese-ethnic users and non-purchasers appear to less adventurous, using in mainstream dishes such as milkshakes, dips and salads (See Table 1).

\section{Purchase behavior}

Most users claim to buy avocadoes at least 'once a week'. The typical place of purchase is in the large supermarket chains such as: NTUC, Giant, Cold Storage, Carrefour and Sheng Shiong, and in dedicated fruits stores around the city. There was no mention of buying at the hawkers centres or wet markets. Generally avocados are considered an expensive fruit. Most claim the price to be ranging from SG\$1 to SGD $\$ 1.50$. Country of origin is believe to affect price, with Indonesian considered cheaper than Australian avocados: "It depends on which country it's from. If it's purchased from Australia, it's more expensive. It's cheaper if it's from Indonesia" (trade purchase).

Choosing an avocado although not difficult can be challenging at times, as respondents find it difficult to determine the ripeness of an avocado. Most believe that ripeness is determined by the colour and weight. Avocados are of a dark colour and heavy weight are believed to be ready for consumption. Ways of properly storing avocadoes were 
not well understood. Some claiming that to ripen you need to place with other fruits or with rice and other storing them in the refrigerator. Respondents find it disappointed when opening up it is bruised on the inside: "The fruit is very sensitive and spoils easily. Sometimes it could look very nice on the outside when it's actually bruised on the inside" (trade purchase).

\section{Barriers to consumption}

Low visibility in supermarket chains and other fruit stores appears to be one of the key barriers affecting consumption. Most claimed that although avocados can be found in international retails stores in the CBD area, they are not easily available in major supermarkets across Singapore. All the groups also considered the high premium to be a deterrent to greater consumption.

For non-users, given its unique appearance and relatively novelty, avocados are not usually in front of mind when doing grocery purchases: "If you look at it the first time you are not sure if it is a fruit or vegetable or something else, so it is difficult to try" (nonpurchase). Lack of knowledge of how to incorporate with local cuisine and no knowledge of appropriate cooking methods were key constrains for non-purchasers. For this group the hassle of choosing and storing avocadoes made the purchasing proposition unattractive.

\section{Country of origin}

Respondents had a vague understanding of country of origin, but few could name countries that were currently supplying the Singaporean market. Furthermore, most they could not identify differences in quality according to place of production. Trade purchases were more discerning on quality and could identify avocadoes from certain countries as more appealing: "Those from Australia and New Zealand are better, have a different texture / aroma especially if you blend them. Australian ones tastes better" (trader)

When prompted, respondents had an overall positive attitude towards Australian produce. For Chinese-ethnic user the Australian food is seen as having traits of quality such as: less pesticides, freshness, greater food safety standards and perceived 'premiumness'. Positive associations of Australian food are also transferred to avocados.

\section{Taste results}

Respondents participated in a tasting exercise to rate Australian avocados on five product attributes: size, first bite, texture, taste and overall rating (Table 3). A rating survey of a 5-point scale, 1 being low acceptance and 5 being high acceptance, was used in the product evaluation. Chinese-ethnic users evaluated more highly their eating experience in all five attributes compared to the other three groups. Surprisingly, Chinese-ethnic users evaluated avocados higher than the average regards to taste than any of the other groups. This dispel the notion that avocados may not be accepted by Chinese-ethnic consumer due to its plain taste. It demonstrates that if consumers are exposed to the taste of avocado, they get accustomed to its flavour.

Respondents also asked to taste using a range of condiments: sugar, salt, pepper and chilli. The most preferred way of eating was with salt, followed by with sugar and with no condiments (Table 4).

\section{Marketing and promotions}


Most respondents do not believe they have seem any marketing material relating to avocados in stores, print media, advertising and/or social media. There was some recollection of avocado being used as an ingredient is facial/skin care products. The only fruit-related advertising recalled referred to the kiwi fruit and Sunkist oranges. A key element of the research was to seek reaction to overall marketing messages trying to convey to Singaporean consumers. A marketing program was going to be launched across three markets: Singapore, Malaysia and Hong Kong and the industry needed feedback on brochures and poster being prepared. Respondents were presented with visuals, messages, brochures and posters. When presented with the range of marketing material the reactions were varied (Table 5).

In Australian the 'delicious meets nutritious' headline was very popular, however in Singapore it was thought that avocados were not delicious, as such but did have a unique taste. For hero images, the Heart image worked better than the Ying-Yang image, as the later was perceived to be too Asian to be associated with an Australian product. A brochure demonstrating how to purchase, store and prepare a variety of Asian-themed dishes was also distributed (see Figure 1). The respondents had in general a positive attitude as the cards showed how to purchase and adapt it to their Asian cuisine. The "Cendol Crush" had the most appeal for all groups.

\section{IMPLICATION}

The research reveals that although avocados are gaining popularity in Singapore markets, consumption is still relatively low, with only a small portion of consumers purchasing them regularly. Avocados tend to be used as 'an ingredient', rather than as the main dish. Most consumers are exposed to the fruit out-of-home, with consumption at home is still limited and confined to be used in very simple dishes in salads and milkshakes. Avocados are not commonly used in Asian cuisine, with most find it difficult to integrate with Chinese cooking.

The key attributes considered important by Singapore buyers when purchasing avocados are: health benefits and versatility. The avocado taste by itself has very low appeal for most consumers, particularly for the Chinese-ethnic consumers. Interestingly, Chinese-ethnic consumers could identify key health benefits such as lowing cholesterol levels and reducing risks associated with heart disease. Barriers to consumption related to the low exposure of consumers to the fruit, as it is not easily accessible in local supermarkets and hawker centers. Even is large foreign-owned supermarkets, respondents reported it was difficult to purchase avocados through the year. Price premiums compared to other more familiar fruits was also a key barrier to consumption.

Australian avocados find acceptance in the market, with most respondents regarding Australia as a supplier of quality, safe, premium fresh produce. Messages linking Australian avocados with health attributes of the fruit and with Australiana imaginary are acceptable. Recipe ideas and information on how to purchase and store avocado for home consumption are also well received.

The result of this research are encouraging for the Australian avocado industry as it confirms that the market in Singapore, and in other countries with strong Chinese influence, can be expanded. Lack of strong historical connection with the fruit does not prevent increased consumption. Furthermore, even though the taste of avocados can be bland and with little appeal to most Chinese-ethnic consumers, the taste by itself is not a major deterrent to purchase. For the Australian industry to engage with Singapore consumers it would need to anchor its messages with the attributes considered important for consumers: 
health properties and versatility. Furthermore, the industry needs to leverage the strength of the Australian country of origin and present itself as a supplier of high quality, safe, fresh produce. This would reinforce the perception that Australian avocados are a healthy ingredient from a trusted supplier.

The Australian industry has started to incorporate the research findings into its market development strategies and bearing the fruit of its success. The export increase of $72 \%$ to Singapore in the last five years, is a testimony of the success of marketing programs based on research.

\section{CONCLUSION}

The study found that although avocados are gaining popularity in Asian markets with Chinese-ethnic population, consumption is still relatively low, with only a small portion of consumers purchasing them regularly. Avocados are not popular with Chinese ethnic consumers, as most find it hard to integrate the fruit in Chinese cooking. However, the low taste profile with Chinese-ethnic consumers is not a deterrent to market development. The positive health attributes of avocados outweigh any concerns regarding taste. Chinese-ethnic consumers once introduced to the fruit and shown ways to accommodate it in their diets, are receptive to using avocados in their cooking or when eating out.

This study concludes that to increase avocado consumption with consumers, greater awareness of the different uses of avocados is needed and more consumer information is required to dispel any confusion about the health attributes of the fruit. As the research was not undertaken in mainland China the findings do not fully reflect the avocado experiences of Chinese consumers. The results of the study only reflect the views of Chinese-ethnic consumers residing in Singapore. The results only provide a glimpse as to what Chineseethnic consumers in other countries, like mainland China, might considered important. Therefore, it would be prudent to undertake a qualitative project in mainland China to gain a deeper understanding of what Chinese consumers consider as important when purchasing avocados. 


\section{Literature Cited}

Attride-Stirling, J. 2001. Thematic networks: an analytic tool for qualitative research. Qualitative research 1(3): 385-405.

Brescia, A. 2012. The Hong Kong Avocado Market. Queensland, Department of Employment, Economic Development and Innovation.

Daly, J., et al. 1997. The public health researcher: A methodological approach, Melbourne, Australia: Oxford University Press.

FreshPlaza 2014. Increasing avocado consumption in China. Retrieved 12 February, 2015, from http://www.freshplaza.com/article/131764/Increasing-avocado-consumptionin-China.

Gale, H. F. and K. Huang 2007. Demand for food quantity and quality in China.

Honan, K. 2014. Australian avocado industry developing Asian export plan. Retrieved 20 February, 2015, from http://www.abc.net.au/news/2014-09-23/australia-avocadoexport-plan/5761546.

Kangde, L. and Z. Jiannan 2000. Avocado production in china. Avocado production in asia and the pacific: 15 .

Leininger, M. M. 1985. Ethnography and ethnonursing: Models and modes of qualitative data analysis. Qualitative research methods in nursing: 33-72.

Marks, C. and M. Bean 2005. Shanghai Fruit and Vegetable Markets. GAIN report. F. A. Services. CH5811.

Morgan, D. L. and R. A. Krueger 1993. When to use focus groups and why.

Sun, X. and R. Collins 2002. Attitudes and consumption values of consumers of imported fruit in Guangzhou, China. International Journal of Consumer Studies 26(1): 34-43.

TradeMap 2015. Trade of avocados 2009-2014. Trade Map. Retrieved 25 February, 2015, from http://www.trademap.org/.

Yu, X. and D. Abler 2009. The demand for food quality in rural China. American Journal of Agricultural Economics 91(1): 57-69. 


\section{Tables}

Table 1. Ways of consuming avocados. Source: researcher own findings.

\begin{tabular}{cccc}
\hline Chinese users & Mixed-ethnicity & Non-purchasers & Trade \\
\hline Dips & Milkshakes with & Milkshake & Vegetarian dishes \\
Milkshake with & gula merikala & Sandwich & Mediterranean \\
honey and sugar & Milk shake with & Salad & cuisine \\
Milkshake with & condensed milk and & & Milkshakes \\
gula merilaka & honey & Burgers \\
& Salad & Sandwiches \\
& Dips & Pizza, quiches \\
& Guacamole & Guacamole dips \\
& Sandwich & Dip for Indian food \\
& Ice-cream & In desserts \\
& By itself with & \\
raisings & & \\
& By itself with & \\
& mustard, olive oil & \\
& and salt & \\
\end{tabular}

Table 2. Barrier to consumption. Source: researcher own findings.

\begin{tabular}{|c|c|c|c|}
\hline Chinese users & Mixed-ethnicity & Non-purchasers & Trade \\
\hline $\begin{array}{l}\text { - Low visibility } \\
\text { in stores } \\
\text { - } \text { Not an } \\
\text { everyday fruit } \\
\text { - } \begin{array}{l}\text { Premium } \\
\text { price }\end{array}\end{array}$ & $\begin{array}{l}\text { - } \text { Bland taste } \\
\text { - Concerns with fat } \\
\text { content: e.g. } \\
\text { weight gain } \\
\text { - Premium price }\end{array}$ & $\begin{array}{l}\text { - Low fit with } \\
\text { Chinese and other } \\
\text { local cuisine } \\
\text { - Difficult when } \\
\text { selecting } \\
\text { - Difficult to store } \\
\text { and prepare } \\
\text { - Premium price }\end{array}$ & $\begin{array}{l}\text { - Low fit with } \\
\text { Chinese } \\
\text { cooking } \\
\text { - Not an } \\
\text { everyday fruit } \\
\text { - Difficult when } \\
\text { selecting } \\
\text { - Premium } \\
\text { price }\end{array}$ \\
\hline
\end{tabular}

Table 3. Product evaluation. Source: researcher own findings.

\begin{tabular}{lccccc}
\hline & $\begin{array}{c}\text { Overall } \\
\text { average } \\
\mathrm{N}=36\end{array}$ & $\begin{array}{c}\text { Chinese } \\
\text { users } \\
\mathrm{N}=9\end{array}$ & $\begin{array}{c}\text { Mixed- } \\
\text { ethnicity } \\
\mathrm{N}=9\end{array}$ & $\begin{array}{c}\text { Non- } \\
\text { purchasers } \\
\mathrm{N}=9\end{array}$ & $\begin{array}{c}\text { Trade } \\
\text { users } \\
\mathrm{N}=9\end{array}$ \\
\hline Size & 4.03 & 4.11 & 3.68 & 3.78 & 4.11 \\
First bite & 4.11 & 4.67 & 4.11 & 3.67 & 4 \\
Texture & 3.91 & 4.22 & 4.11 & 4 & 3.78 \\
Taste & 3.94 & 4.67 & 3.89 & 3.44 & 3.78 \\
Overall rating & 3.97 & 4.44 & 3.89 & 3.78 & 3.78 \\
\hline
\end{tabular}



Table 4. Reactions to taste. Source: researcher own findings.

\begin{tabular}{|c|c|c|}
\hline Usage & Strengths & Weakness \\
\hline As is & $\begin{array}{l}\text { Nice, cheesy, creamy and } \\
\text { nutty taste } \\
\text { For a few, unique - } \\
\text { "Special taste, like } \\
\text { custard" }\end{array}$ & $\begin{array}{l}\text { - A little watery and bland for some users/ } \\
\text { trade purchasers } \\
\text { (Trade) - Seems a bit too bitter } \\
\text { - (Non-purchasers) - Neutral taste, but feels } \\
\text { plain like something's missing }\end{array}$ \\
\hline $\begin{array}{l}\text { With } \\
\text { salt }\end{array}$ & $\begin{array}{l}\text { Appealing } \\
\text { Flavourful, , helps add to } \\
\text { the taste }\end{array}$ & - For a few, strange taste \\
\hline $\begin{array}{l}\text { With } \\
\text { pepper }\end{array}$ & None & - Unappealing taste experience \\
\hline $\begin{array}{l}\text { With } \\
\text { chilli }\end{array}$ & $\begin{array}{l}\text { - A new taste } \\
\text { experience }\end{array}$ & $\begin{array}{l}\text { - Unappealing taste experience } \\
\text { - Recommended chillis with Avocado- } \\
\text { 'sambal' or 'belechan chilli' instead, a } \\
\text { Malay-style chilli paste }\end{array}$ \\
\hline
\end{tabular}

Table 5. Reactions to posters. Source: researcher own findings.

\begin{tabular}{|c|c|}
\hline Adcepts & Reactions \\
\hline 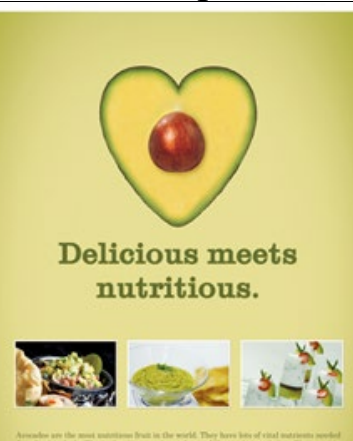 & $\begin{array}{l}\text { 1. Headline (Delicious meets nutritious) - low appeal and } \\
\text { connect } \\
\text { - Delicious not the appropriate descriptor for Avocados } \\
\text { 2. 'Heart' visual - catchy and appealing } \\
\text { - Strongly cues health benefits } \\
\text { - For a few, cues taste delight } \\
\text { 3. Kangaroo with seed - low pick } \\
\text { - On probing, appreciated and considered an apt symbol } \\
\text { for an Australian Avocados }\end{array}$ \\
\hline - 18 & \\
\hline 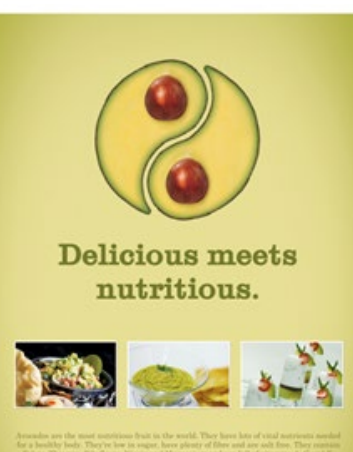 & $\begin{array}{l}\text { 1. Headline (Delicious meets nutritious) - low appeal and } \\
\text { connect } \\
\text { - Delicious not the appropriate descriptor for Avocados } \\
\text { 2. 'Yin Yang' visual - evokes polarized reactions } \\
\text { - Use of Chinese religious symbols inappropriate } \\
\text { - Low fit with the descriptors of 'Australian' Avocado } \\
\text { 3. Kangaroo with seed - low pick } \\
\text { - On probing, appreciated and considered an apt symbol } \\
\text { for an Australian Avocados }\end{array}$ \\
\hline 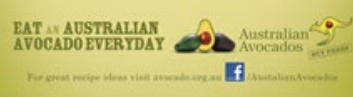 & \\
\hline
\end{tabular}


Figures
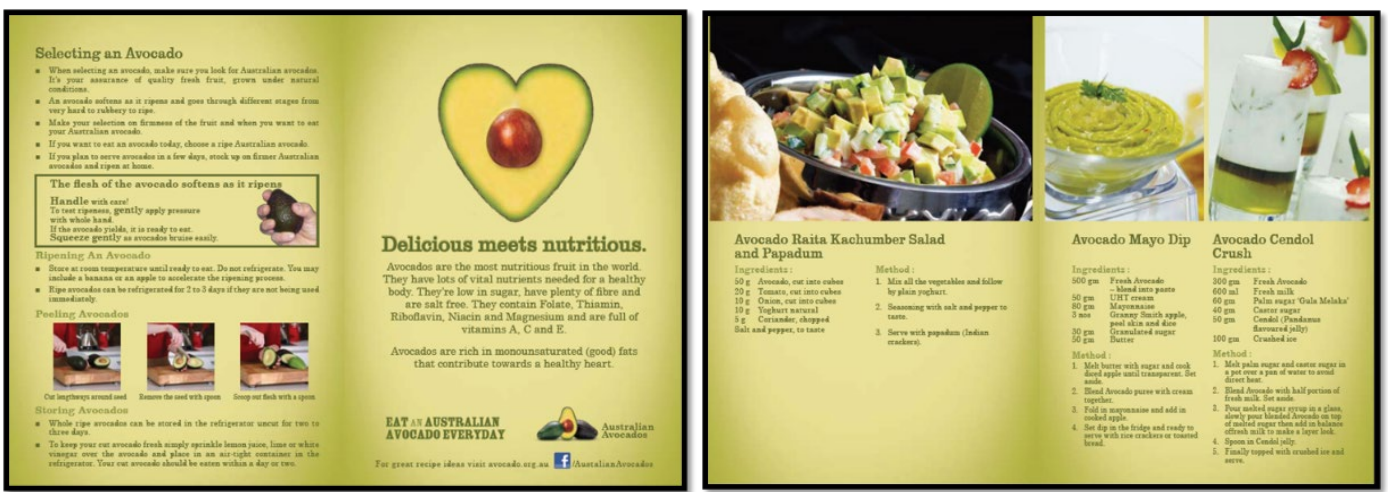

Fig. 1. Avocado brochu 